\title{
PROPHYLACTIC EFFECT OF COENZYME Q10 ON GROSS PARAMETERS OF RAT TESTIS EXPOSED TO MOSQUITO COIL SMOKE INHALATION
}

\author{
Muhammad Fahad Atta, Khadija Qamar, Maria Iram, Saba Saleem Safdar, Tayyaba Faisal, Maryam Shan* \\ Army Medical College/National University of Medical Sciences (NUMS) Rawalpindi Pakistan, *HBS Medical \& Dental College, Islamabad Pakistan
}

\begin{abstract}
Objective: To determine the toxic effect of mosquito coil smoke inhalation on gross parameters of rat testis and explore the protective effect of Coenzyme Q10on testicular toxicity profile.

Study Design: Laboratory-based experimental study.

Place and Duration of Study: Department of Anatomy Army Medical College, Rawalpindi in collaboration with National Institute of Health, Islamabad, from Jan 2020 to Dec 2020.

Methodology: This study was carried out among 30 male Sprague Dawley rats, distributed into three groups as 10 rats/group; group A served as control group, rats in group B were exposed to allethrin-based mosquito coil smoke 4 hours/day for 12 weeks. Rats in group C were administered Coenzyme Q10 (10 mg/kg/day) via oral gavage for 12 weeks along with mosquito coil smoke exposure. At the end of study, gross parameters of body weight gain, testicular weight and volume, and relative tissue body weight index of testis were compared among groups.

Results: Rats exposed to mosquito coil smoke alone showed significantly less weight gain $(p<0.001)$ ), testicular weight $(p<0.001)$, volume $(p<0.001)$, and relative tissue body weight index $(p<0.001)$ as compared to control group. Rats administered Coenzyme Q10 along with mosquito coil smoke exposure exhibited significantly higher weight gain $(p<0.001)$, testicular weight $(p<0.001)$, volume $(p<0.001)$ and relative tissue body weight index $(p<0.001)$ as compared to rats exposed to mosquito coil smoke alone.

Conclusion: Long-term inhalation of allethrin-based mosquito coil smoke caused testicular atrophy among rats, as evident by reduced testicular weight, volume and relative tissue body weight index. Whereas, prophylactic oral administration of Coenzyme Q10 among rats exposed to mosquito coil smoke prevented testicular toxicity.
\end{abstract}

Keywords: Allethrin, Coenzyme q10, Mosquito coil, Relative tissue body weight index, Testis, Weight.

This is an Open Access article distributed under the terms of the Creative Commons Attribution License (http://creativecommons.org/licenses/by/4.0), which permits unrestricted use, distribution, and reproduction in any medium, provided the original work is properly cited.

\section{INTRODUCTION}

Mosquito-borne diseases account for the maximum number of cases, morbidity, and mortality among all vector-borne infectious diseases, worldwide ${ }^{1}$. Tropical and subtropical regions of the world (Africa, Asia, and America) are the most widely affected by these mosquito-borne diseases ${ }^{2}$, where approximately more than half of the human population is residing. Despite the availability of modern non-chemical methods to control mosquitoes ${ }^{3}$, chemical mosquito repellents are still the most widely used especially in low socio-economic regions ${ }^{4}$. Most abundantly used household chemical repellants include mosquito coils, pyrethrumbased sprays, vaporizer mats and aerosols ${ }^{5}$. As per careful estimate, approximately $45-80 \%$ of deterrence can be achieved via pyrethrin-based mosquito coils within the first 4 weeks of treatment ${ }^{6}$.

Mosquito repellant action of coils, vaporizer mats, and emanators includes spatial action of vaporous/ airborne pyrethroid particles, as recommended by

Correspondence: Dr Muhammad Fahad Atta, Department of Anatomy, Army Medical College Rawalpindi Pakistan

Received: 30 Dec 2020; revised received: 19 Feb 2021; accepted: 18 Mar 2021
$\mathrm{WHO}^{6,7}$. Among which mosquito coils are less desirable because of the production of smoke as side product $^{6}$. Despite the side effect of smoke, mosquito coils are still widely used in regions of Asia, Africa, and Australia7, owing to their easy accessibility and costeffectiveness. Pyrethroid compounds are experimentally reported to cause impaired male reproductive functions among rodents and human, either via oxidative stress or endocrinal disruption of Hypothalamicpituitary gonadal axis ${ }^{8}$. Owing to the widespread domestic use, cumulative results of long-term exposure to mosquito coil smoke can be a matter of reproductive health concern?

According to a recent review, environmental exposure is more important in causing male reproductive disorders via epigenetic mutations as compared to genetically acquired causes ${ }^{9}$. As our knowledge regarding responsible environmental factors is still lacking, the effect of long-term exposure to mosquito coil smoke on the male reproductive system should be explored to allow timely prevention and treatment.

Owing to the potential antioxidant role of Coenzyme Q10 (CoQ10), its administration has shown 
promising results of improved seminal parameters in experimental trials among humans and rodents ${ }^{10}$. However, there is lack of any substantial study to see the effects of CoQ10 on testis. Hence, the objective of this study was to determine the effects of mosquito coil smoke on the testicular weight toxicity of rats and explore the protective effect of Coenzyme Q10 on testicular toxicity.Testicular weight, volume and RTBWI, if taken as an indirect indicator of testicular atrophy, can be corelated with reduced fertility and sperm abnormalities in future clinical studies to have conclusive remarks on mosquito coil smoke toxicity profile.

\section{METHODOLOGY}

This laboratory-based experimental study was carried out at the department of Anatomy, Army Medical College, Rawalpindi/National University of Medical Sciences (NUMS) in collaboration with the National Institute of Health (NIH), Islamabad with approval from Ethics Review Committee (ERC/ID/ 104). The research was carried out on 30 male Sprague Dawley rats from January to December 2020. Healthy rats of average 3-4 months of age and mean weight of $250 \pm 50$ gm were selected by non-probability consecutive sampling. Rats with any gross abnormality were excluded from the study.

Environment, housing, and management of rats were carried out under NRC, 1996 declaration ${ }^{11}$, and institutional guidelines throughout the research process. The rats were fed on standard laboratory rat chow and water ad libitum. After an acclimatization period of one week, rats were distributed into three groups including 10 rats per group as:

Group A: Rats in Group A served as controls.

Group B: These rats were exposed to the smoke of the mosquito coil (Allethrin-based) four hourly/day for 12 weeks ${ }^{12}$.

Group C: Rats in this group were given Coenzyme Q10 in a dose of $10 \mathrm{mg} / \mathrm{kg} /$ day, orally through a gavage tube 13 along with exposure to mosquito coil smoke (Allethrin-based) four hourly/day for 12 weeks.

Rats cages for mosquito coil smoke exposure were placed in transparent plastic cabins measuring $76 \times 60$ x $60 \mathrm{~cm}$. Plastic cabins had three small openings on either side, each with a width of two $\mathrm{cm}^{13,14}$. Rats in Group B and C were exposed via whole-body inhalation to smoke of commercially available mosquito coil with an active ingredient of d-trans Allethrin (one g/ $\mathrm{kg}$ ) for four hours (10am-2pm) every day for 12 weeks. Pure salt of Coenzyme Q10 was administered to rats in group $C$ in dose of $10 \mathrm{mg} / \mathrm{kg}$, between (9am-10am) every day for 12 weeks, by trained personnel orally through gavage tube ${ }^{13}$.

The bodyweight of the rats was measured in grams at start and end of the experiment, with the help of digital analytical balance, sensitive up to one-tenth of a gram increment. At the end of the study, animals were euthanized by inhalant anesthetic overdose of diethyl ether. The rats was dissected in the supine position, by makinga longitudinal midline incision below the rib cage to cut through skin and muscles and open the abdominal cavity. Right testes were identified, retracted through the inguinal canal into the abdominal cavity, and removed.

The volume of testes was measured in milliliter using formalin displacement method ${ }^{15}$. The weight of the testis was then measured in grams using a digital analytical balance (Sartorius CP 324S), sensitive to weight increment of 0.0001 gram. Relative Tissue Body Weight Index (RTBWI) was calculated to get standardize the weight of the testis over rats of different sizes, using the following formula ${ }^{16}$.

$$
\text { RTBWI }=\frac{\text { weight of testis in grams }}{\text { weight of body in grams }} \times 100
$$

The data was entered into the database using a statistical package for social sciences (SPSS-22). Quantita-tive variables were expressed as mean \pm standard deviation. Significant difference among groups was determined by using one-way analysis of variance (ANOVA) after verification of the assumptions. Outliers in data were assessed by inspection of boxplot for values $>1.5$ box-lengths from the edge of the box. Normally of data was determined for each group by visual inspection of Q-Q plots and confirmed by the ShapiroWilk test $(p>0.05)$. Homogeneity of variances was assessed by Levene's Test of Homogeneity of Variance ( $p$ $>0.05$ ). Data significant for overall F-Test of one-way ANOVA were followed by post hoc Tukey test to determine pairwise differences among groups. Data with non-homogenous distribution was analyzed by WelchANOVA, and followed by Games-Howell post hoc test. The $p$-value $\leq 0.05$ was considered signifi-cant.

\section{RESULTS}

Total 30 healthy male rats of average weight of $305.06 \pm 3.04$ grams were included in the study. Mean weight of rats in the beginning and the end of study among each group are given in table-I. One-way ANOVA was conducted to analyze the toxic effects of mosquito coil smoke and the protective effect of coen- 
zyme Q10 on the body weight gain, testicular weight, volume and RTBWI among groups, after satisfying the assumptionsof outliers, normality and homogeneity. alone, a statistically significant difference of $17.6 \mathrm{gm}$, $95 \%$ CI (16.2 to $19 \mathrm{gm}), p<0.001$. Whereas, the group B rats exposed to mosquito coil smoke alone had lost

Table-I: Inferential statistics of parameters among groups ( $n=10 /$ group).

\begin{tabular}{|c|c|c|c|c|c|}
\hline Parameter & Group A & Group B & Group C & Total & $p$-value \\
\hline Initial Weight $(\mathrm{gm})^{*}$ & $305.16 \pm 2.65$ & $304.88 \pm 2.90$ & $305.14 \pm 3.77$ & $305.06 \pm 3.04$ & 0.98 \\
\hline Final Weight $(\mathrm{gm})^{*}$ & $324.42 \pm 1.86$ & $301.74 \pm 3.49$ & $319.60 \pm 3.44$ & $315.25 \pm 10.34$ & $<0.001^{*}$ \\
\hline Weight Diff. $(\mathrm{gm})^{*}$ & $19.26 \pm 2.1$ & $-3.14 \pm 1.5$ & $14.46 \pm 0.76$ & $10.19 \pm 9.91$ & $<0.001^{*}$ \\
\hline Testis Weight $(\mathrm{gm})^{*}$ & $1.74 \pm 0.02$ & $1.13 \pm 0.02$ & $1.54 \pm 0.05$ & $1.47 \pm 0.26$ & $<0.001^{*}$ \\
\hline Testis Volume (ml) & $1.8 \pm 0.09$ & $1.1 \pm 0.08$ & $1.55 \pm 0.07$ & $1.48 \pm 0.31$ & $<0.001^{*}$ \\
\hline Testicular Relative* tissue body weight index & $0.54 \pm 0.01$ & $0.37 \pm 0.02$ & $0.48 \pm 0.01$ & $0.46 \pm 0.07$ & $<0.001^{*}$ \\
\hline \multicolumn{6}{|c|}{ Table-II: Pairwise comparison of parameters among groups (n=10/group). } \\
\hline Group Comparison & \multicolumn{2}{|c|}{$\begin{array}{l}\text { Group-A } \\
\text { Vs. Group-B }\end{array}$} & $\begin{array}{c}\text { Group-A } \\
\text { Vs. Group-C }\end{array}$ & \multicolumn{2}{|c|}{$\begin{array}{l}\text { Group-B } \\
\text { Vs. Group-C }\end{array}$} \\
\hline Weight Gain* & \multicolumn{2}{|c|}{$<0.001^{*}$} & $<0.001^{*}$ & \multicolumn{2}{|c|}{$<0.001^{*}$} \\
\hline Testis Weight* & \multicolumn{2}{|c|}{$<0.001^{*}$} & $<0.001^{*}$ & \multicolumn{2}{|c|}{$<0.001^{*}$} \\
\hline Testis Volume & \multicolumn{2}{|c|}{$<0.001^{*}$} & $<0.001^{*}$ & \multicolumn{2}{|c|}{$<0.001^{*}$} \\
\hline Testicular Relativetissue body weight index* & \multicolumn{2}{|c|}{$<0.001^{*}$} & $<0.001^{*}$ & \multicolumn{2}{|c|}{$<0.001^{*}$} \\
\hline
\end{tabular}

Mean weight gained by rats from start till the end of the experiment was statistically significantly different between the groups, Welch's F $(2,15.39)=595.58$, $p<0.001$. Games-Howell post hoc analysis revealed that
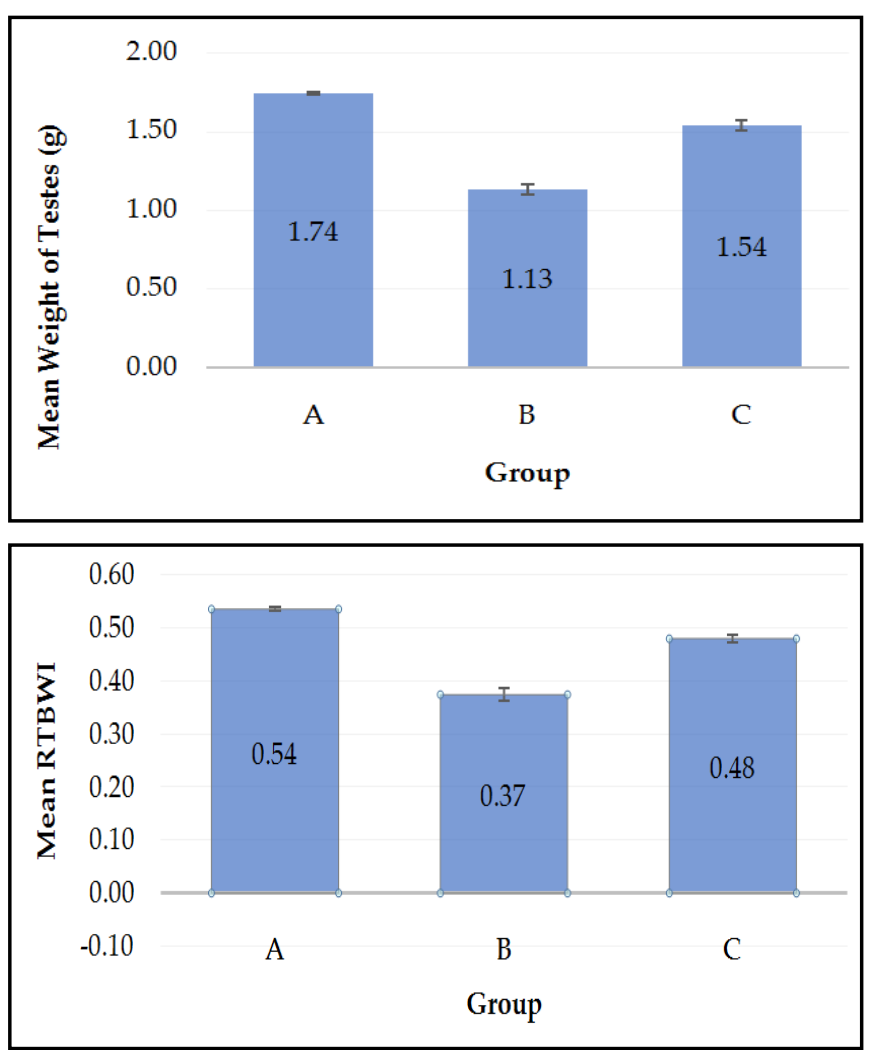

weight till the end of the study, by an average of $3.14 \pm$ $1.5 \mathrm{gm}$, figure.

The mean weight (Welch's F $(2,14.46)=961.1, p$ $<0.001)$, volume $(\mathrm{F}(2,27)=183.65, p<0.001)$ and RTBWI
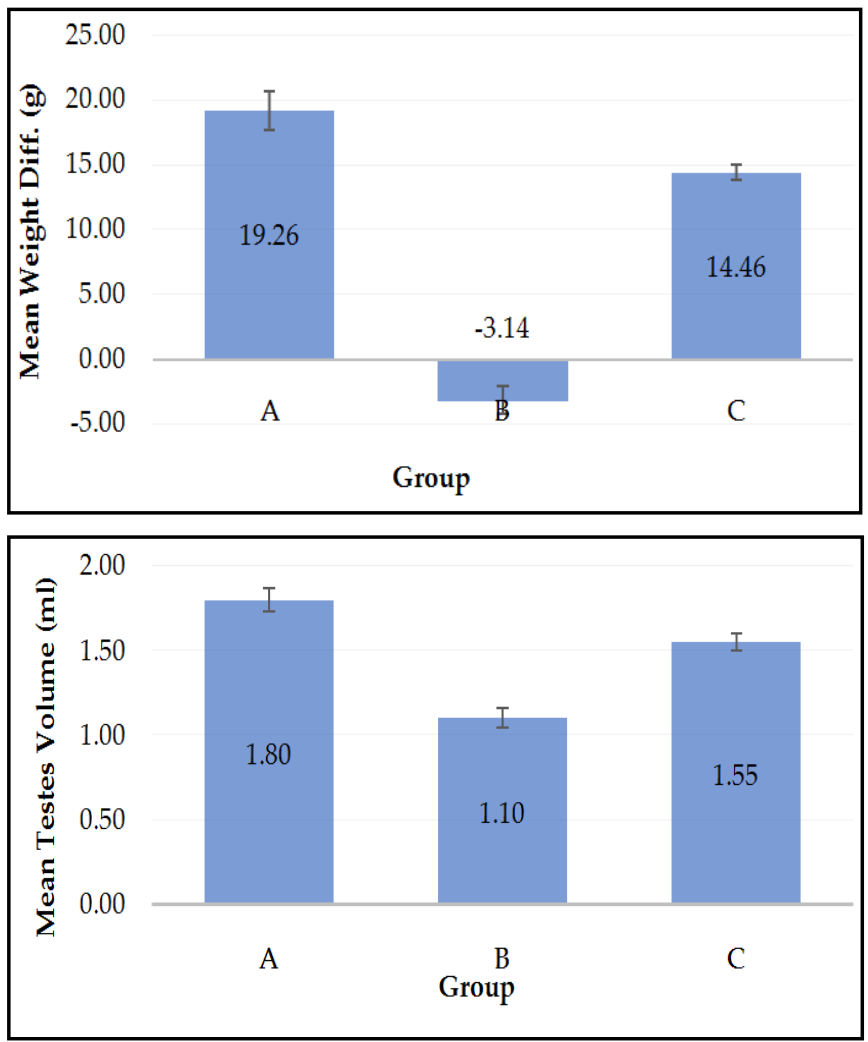

Figure: Mean values of weight gain, weight, volume, and relative body weight index of testis.

group C i.e., rats given CoQ10 along with exposure to mosquito coil smoke gained more weight as compared to group $B$ i.e., the rats exposed to mosquito coil smoke
$($ Welch's F $(2,15.82)=505.15, p<0.001)$ of rat testis varied significantly between study groups. Post hoc analysis revealed that weight, volume and RTBWI of rats' 
testis in group $C$ was significantly higher as compared to group B, table-II. However, the weight, volume and RTBWI of rats'testis in group C, was significantly less as compared to the control group A, table-II.

Data given as mean \pm standard deviation, group $A=$ control group, group $B=$ rats exposed to mosquito coil smoke, group $C=$ rats administered CoQ10 along with mosquito coil smoke exposure, weight diff $=$ difference between rats' weight at start and end of experiment, $p$-value $=$ significant at $p \leq 0.05$ for overall F-test of One-way ANOVA, *Parameters distributed non-homogenously are depicting Welch-ANOVA statistics.

Group $A=$ control group, group $B=$ rats exposed to mosquito coil smoke, group $\mathrm{C}=$ rats administered $\mathrm{CoQ}$ 10 along with mosquito coil smoke exposure, Weight Diff=Difference between rats' weight at start and end of experiment, RTBWI=Relative tissue body weight index of the testis, $p$-value $=$ significant at $p \leq 0.05$ for post hoc Tuckey test of One-way ANOVA, *Parameters distributed non-homogenously are followed up by Games-Howell Test.

Group $A=$ control group, group $B=$ rats exposed to mosquito coil smoke, group $C=$ rats administered CoQ 10 along with mosquito coil smoke exposure, error bars at $95 \%$ confidence interval, weight diff=difference between rats' weight at start and end of experiment, RTBWI=Relative tissue body weight index.

\section{DISCUSSION}

Owing to the increasing burden of male infertility worldwide, responsible and preventable environmental factors need to be explored. Among the known causes of male reproductive disorders, almost $30-80 \%$ of cases worldwide include oxidative stress ${ }^{17,18}$. Pyrethroid chemicals, the major constituents of mosquito coils, are linked with oxidative stress in male reproductive system by experimental evidence. Therefore, it can be speculated that long-term mosquito coil smoke inhalation can be a causative factor of male reproductive functional and structural impairment. Based on the proposition and antioxidant potential of Coenzyme Q10 (CoQ10), this study was designed to determine the detrimental effects of mosquito coil smoke on the rat testes and the protective effect of CoQ10. Comparison of gross features i.e., body weight gain, testicular weight and volume, relative tissue body weight index (RTBWI), of rats' testis was done among the study groups at the end of the study.

Our study showed that the control group gained more weight as compared to those exposed to mosq- uito coil smoke over the duration of the study. However, the rats administered CoQ10 along with mosquito coil smoke exposure gained significantly more weight as compared to the rats exposed to the smoke alone. A similar trend was seen when other gross features were compared among groups. The control group had significantly higher mean testicular weight, volume, and RTBWI as compared to the Experimental groups. Protective effect of CoQ10 was evident by the fact that rats administered CoQ10 along with mosquito coil smoke had significantly higher testicular weight, volume, and RTBWI as compared to the rats exposed to mosquito coil smoke alone. Although, exact histopathologic changes are the more sensitive indicator of testicular damage, still decrease in testis weight and volume can be ascribed to generalized testicular degeneration as seen in comparable previous studies ${ }^{12,14,15}$. In 2013, Alalwani reported significantly decreased relative testicular weight among experimental rats as compared to the control group $(p=0.014)$ in association with histopathological findings of testicular degeneration ${ }^{14}$. Current study has compared not only the absolute testicular weight among groups, but also the relative testicular weight with respect to total body weight, hence eliminating the potential bias of different body sizes.

The pathophysiologyof this gross variation can beexplained by sloughing of the tubular epithelial cells caused by oxidative stress, and thus indicating gonadal toxicity by cell loss. The findings of reduced testicular weight, volume and RTBWI can also be attributed towards anti-progestogenic nature of Pyrethroids ${ }^{19}$. As the $95 \%$ fluid produced in seminiferous tubules is reabsorbed across rete testis, efferent ducts, and epididymis under the influence of estrogens ${ }^{19}$. Pyrethroids being able to inhibit estrogen receptors can decrease this fluid reabsorption. Which may lead to fluid accumulation and building up of backpressure along efferent ducts as well as seminiferous tubules. Longstanding pooling/backpressure may lead to damage and ultimately atrophy of germinal epithelium and interstitial cells of seminiferous tubules ${ }^{19}$, as indicated by gross morphometric findingsin current study. Reduced mean testicular weight, volume and RTBWI, if taken as an indirect indicator of testicular atrophy, can be corelated with reduced fertility and sperm abnormalities as seen in human cohorts and rodents exposed to longterm pyrethroids ${ }^{20-22}$. After exposure to mosquito coil smoke to a rodent model, Madhubabu in 2012 reported oxidative distress and distorted cytoarchitecture in male reproductive tract, along with decreased sperma- 
togenesis ${ }^{12}$. Again in 2017, Madhubabu reported compromised spermatogenesis, sperm maturation and steroidogenesis in adult rats exposed to mosquito coil smoke in perinatal life ${ }^{22}$. Compromised semen and male reproductive hormonal profile has been reported among human cohorts exposed to pyrethroids by Radwan in 2014, but their association with testicular histomorphological features still need to be explored ${ }^{20}$.

Decreased testicular size and volume in presence of reduced Testosterone levels, can be attributed to testicular atrophy or reduced fluid production by Sertoli cells of seminiferous tubules ${ }^{8}$. Imbalanced reproductive endocrinology upon mosquito coil smoke exposure can be also be caused by oxidative stress induced damage to the Leydig cells, as indicated experimentally among human and rodent studies ${ }^{8}$. Bodyweight loss seen among rats exposed to mosquito coil smoke can also be related with hypothalamic-pituitary-gonadal axis imbalance ${ }^{23}$, that could have led to impaired Testosterone production and hence testicular atrophy.

Antioxidants supplementation has been shown to improve oxidative stress-induced male reproductive disorders. The rats administered CoQ10 with mosquito coil smoke exposure had higher testicular weight, volume, and RTBWI as compared to the rats exposed to mosquito coil smoke alone. Substantial data is unavailable on the direct effect of CoQ10 on rats' testis exposed to mosquito coil smoke to allow a healthy comparison with this study. However, the beneficial effects of CoQ10 administration on sperm parameters are supported by metanalysis of available data by Lafuente $e t a l^{10}$. Spermatozoa carry a large number of mitochondria for their remarkable energy needs. In addition, the spermatozoa are at high risk of oxidative stress for carrying a high proportion of unsaturated lipids in their cell membranes and continuous exposure of free radicals being produced. For both reasons, CoQ10 plays an essential role in male reproductive physiology owing to its bioenergetic and antioxidant characteristics. This study has major limitation of not assessing the exact histopathological variation of testis and sper-matogenic count to give conclusive remarks on mosq-uito coil testicular toxicity. Despite the limitations, this study is unique in exploring the effects of long-term exposure to mosquito coil smoke on testicular weight toxicity while assessing the protective effects of CoQ10 at the same time.

\section{CONCLUSION}

Long-term inhalation of allethrin-based mosquito coil smoke caused testicular atrophy among rats, as evident by reduced testicular weight, volume and RTBWI. Whereas, prophylactic oral administration of CoQ10 among rats exposed to mosquito coil smoke ameliorated adverse effects on testis.

\section{CONFLICT OF INTEREST}

This study has no conflict of interest to be declared by any author.

\section{REFERENCES}

1. Organization WH. Ethical issues associated with vector-borne diseases: report of a WHO scoping meeting, Geneva, 23-24 February 2017. World Health Organization; 2017. Available at: https://apps.who.int/iris/bitstream/handle/10665/259687/wh o-htm-ntd-vem-2017.07-eng.pdf

2. Organization WH. Regional Office for South-East Asia. Anopheline species complexes in South and South-East Asia. WHO Regional Office for South-East Asia; 2007. Available at: https:// apps.who.int/iris/handle/10665/204779

3. Naseem S, Malik MF, Munir T. Mosquito management: A review. J Entomol Zool Stud 2016; 4(5): 73-79.

4. Omodior O, Luetke MC, Nelson EJ. Mosquito-borne infectious disease, risk-perceptions, and personal protective behavior among US international travelers. Prev Med Rep 2018; 12(1): 336-42.

5. Hazra DK, Samanta A, Karmakar R, Sen K, Bakshi P. Mosquito vector management knowledge, attitude, practices and future of user \& environment friendly new generation botanical mosquitocide formulations. A review Int J Chem Stud 2017; 5(3): 32-37.

6. Ogoma SB, Moore SJ, Maia MF. A systematic review of mosquito coils and passive emanators: defining recommendations for spatial repellency testing methodologies. Parasit Vectors 2012; 5(1): 287-90.

7. Salvi D, Limaye S, Muralidharan V, Londhe J, Madas S, Juvekar $\mathrm{S}$, et al. Indoor particulate matter $<2.5 \mu \mathrm{m}$ in mean aerodynamic diameter and carbon monoxide levels during the burning of mosquito coils and their association with respiratory health. Chest 2016; 149(2): 459-66.

8. Guvvala PR, Ravindra JP, Selvaraju S. Impact of environmental contaminants on reproductive health of male domestic ruminants: a review. Environ Sci Pollut Res 2020; 27(4): 1-18.

9. Skakkebaek NE, Rajpert-De Meyts E, Buck Louis GM, Toppari J, Andersson AM, Eisenberg ML, et al. Male reproductive disorders and fertility trends: influences of environment and genetic susceptibility. Physiol Rev 2016; 96(1): 55-97.

10. Lafuente R, González-Comadrán M, Solà I, López G, Brassesco M, Carreras R, et al. Coenzyme Q10 and male infertility: a metaanalysis. J Assist Reprod Genet 2013; 30(9): 1147-56.

11. Council NR. Guide for the care and use of laboratory animals: National Acad Press 2010; 1(1): 1-246.

12. Madhubabu G, Yenugu S. Effect of continuous inhalation of allethrin-based mosquito coil smoke in the male reproductive tract of rats. Inhal Toxicol 2012; 24(3): 143-52.

13. El-Sheikh AA, Morsy MA, Mahmoud MM, Rifaai RA, Abdelrahman AM. Effect of coenzyme-Q10 on doxorubicin-induced nephrotoxicity in rats. Adv Pharmacol Sci 2012; 2012(1): 981461-65.

14. Alalwani AD. Histopathological study on acrylamide induced testicular changes in adult male rats. Am Based Res 2013; 2(7): 104-09.

15. Szpinda M, Paruszewska-Achtel M, Woźniak A, Mila-Kierzenkowska C, Elminowska-Wenda G, Dombek M, et al. Volumetric growth of the liver in the human fetus: an anatomical, hydrostatic, and statistical study. Biomed Res Int 2015; 2015(1): 1-8. 
16. Wang J, Zhu H, Wang K, Yang Z, Liu Z. Protective effect of quercetin on rat testes against cadmium toxicity by alleviating oxidative stress and autophagy. Environ Sci Pollut Res 2020; 27(20): 25278-86.

17. Wang X, Martínez MA, Dai M, Chen D, Ares I, Romero A, et al. Permethrin-induced oxidative stress and toxicity and metabolism. A review. Environ Res 2016; 149(1): 86-04.

18. Alahmar AT, Calogero AE, Sengupta P, Dutta S. Coenzyme Q10 improves sperm parameters, oxidative stress markers and sperm DNA fragmentation in infertile patients with idiopathic oligoasthenozoospermia. World J Men's Health 2021; 39(2): 346-51.

19. Hess R, Carnes K. The role of estrogen in testis and the male reproductive tract: a review and species comparison. Anim Reprod 2018; 1(1): 5-30.

20. Radwan M, Jurewicz J, Wielgomas B, Sobala W, Piskunowicz M,
Radwan P, et al. Semen quality and the level of reproductive hormones after environmental exposure to pyrethroids. J Occup Environ Med 2014; 56(11): 1113-19.

21. Jurewicz J, Radwan M, Sobala W, Radwan P, Jakubowski L, Wielgomas B, et al. Exposure to widespread environmental endocrine disrupting chemicals and human sperm sex ratio. Environ Pollut 2016; 213(1): 732-40.

22. Madhubabu G, Yenugu S. Exposure to allethrin-based mosquito coil smoke during gestation and postnatal development affects reproductive function in male offspring of rat. Inhal Toxicol 2017; 29(8): 374-85.

23. Shpakov AO, Ryzhov JR, Bakhtyukov AA, Derkach KV. The regulation of the male hypothalamic-pituitary-gonadal axis and testosterone production by adipokines. Advances in Testosterone Action Rijeka, Croatia: Intech Open 2018: 1(1): 25-57. 